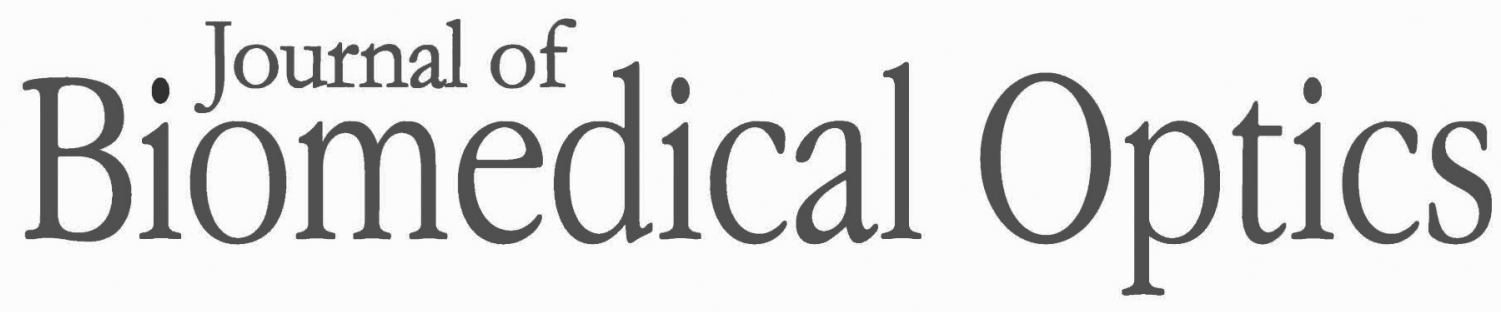

Publisher's Note: Three-dimensional anterior segment imaging in patients with type 1 Boston Keratoprosthesis with switchable full depth range swept source optical coherence tomography

Raju Poddar

Dennis E. Cortés

John S. Werner

Mark J. Mannis

Robert J. Zawadzki 


\section{Publisher's Note: Three-dimensional anterior segment imaging in patients with type 1 Boston Keratoprosthesis with switchable full depth range swept source optical coherence tomography}

Raju Poddar ${ }^{a, b}$ Dennis E. Cortés ${ }^{b}$ John S. Werner ${ }^{a, b}$ Mark J. Mannis $^{b}$, and Robert J. Zawadzki ${ }^{a, b}$

aUniversity of California Davis, Vision Science and Advanced Retinal Imaging Laboratory (VSRI), Sacramento, California 95817

bUniversity of California Davis, Department of Ophthalmology \& Vision Science, Sacramento, California 95817

[DOI: 10.1117/1.JBO.18.8.089802]

This article [J. Biomed. Opt. 18, 086002 (2013)] was originally published online on 2 August 2013 with an error in the author list. The first author's name was reversed, and should be "Raju Poddar" as it appears above.

This article was corrected online on 27 August 2013. It appears correctly in print. 